\title{
Relationship between Emotional Intelligence and Job Performance: A Study in Indian Context
}

\author{
Priyam Dhani*, Anil Sehrawat and Tanu Sharma \\ Department of Humanities and Social Sciences, Jaypee University of Information Technology, \\ Waknaghat - 173234, Solan, Himachal Pradesh India; \\ priyam.dhani@mail.juit.ac.in, anil.sehrawat@juit.ac.in, \\ tanu.sharma@juit.ac.in
}

\begin{abstract}
Objectives: The aim of this study is to examine the relationship between Emotional Intelligence (EI) and Job Performance among middle-level management in Indian organisations. Methods/Statistical Analysis: The sample for this study includes 685 managers from five different sectors in India (banking, power, health care, IT and advertising). The data was collected with the help of self report measures i.e. DKEIT used to measure EI and JPI used to gauge the job performance of employees. SPSS 23 was used for statistical analysis. Correlation and regression analysis was performed to find the relationship between the dependent and independent variables. The stepwise regression models provide support for the association between EI and job performance. Findings: Employees with high EI are said to have better working relationships with other employees and they reflect higher integrity (Rosete, Ciarrochi, 2005) because they can foster better and positive interactions which thereby lead to better performance (Wong, Law, 2002; Dhani, Sharma, 2016). The results of our study are in line with this and state that employee with high EI are better at team work, punctual, accurate, and more competent as compared to the ones who score low on EI. In accordance with theoretical predictions, EI along with all its components; Emotional Perception, Emotional Appraisal and Emotional Regulation was significantly correlated to all indicators of Job performance, including: Punctuality, competence, accuracy and team work. The present study contributes to a growing body of literature seeking to find the relationship between EI and Job Performance, suggesting EI is one of the best known predictors of job performance. This is one of the first studies where self report measures DKEIT and JPI are used, which makes this study unique. Both of the tools are developed in India which adds value to the study. Application/Improvements: The sample of the study is delimited to middle level management from five service sectors, which is not truly representative of all the employees in the organization and the study can be expanded to the employees of the entire organization and other sectors.
\end{abstract}

Keywords: Emotional Intelligence, Indian Context, Job Performance, Middle Level Management

\section{Introduction}

The era of work is changing quickly, consistently similar to the organizations and individuals who work for them. Expanding technological change, globalization, competition, the development of the service industry and delivery speed, runs as an inseparable unit with expanding performance demands. Moreover, to deliver remarkable performance human resources today are required to be greatly engaged in their work, physically, as well as emotionally 1 . Thus, in to survive and to hold a competitive advantage, organizations are putting more pressure on their workers to perform.

Emotions are a perplexing condition of feeling that will influence the idea and conduct, physical and psycho-

*Author for correspondence 
logical changes 2 . Numerous studies ordinarily observed emotions as a negative impact and were scattered intrusion of mental working that obstacle consistent thought ${ }^{3}$. Conversely, different studies have observed that emotions are crucial to rational thinking ${ }^{4}$. Coleman ${ }^{5}$ likewise saw emotions as positive and vital in making an appropriate decision. Emotions likewise affect the choices through certainly moulding the states of mind and judgments.

The idea of emotional intelligence has turned into a well-known subject in the psychological studies in present time and draws more attention ${ }^{6}$. Organization requires interpersonal communications to perform its objectives, and most employments require the capacity to oversee emotions. This purpose of this research is to compile the work done on the relationship between EI and Job performance subsequently adding to the literature on the same. Besides, this research intends to find the relationship between Emotional Intelligence and Job Performance in the Indian context.

\subsection{Emotional Intelligence}

According to Goleman ${ }^{7}$, there are various meanings of emotional intelligence, which are corresponding, intended to comprehend the abilities and traits related to one's own and others' emotions. In the view of Caruso ${ }^{8}$, emotional intelligence includes three criteria keeping so to be viewed as genuine intelligence:

1. Conceptual (can be depicted as an arrangement of abilities);

2. Correlation (the measures correspond with different measures which reflect comparable aptitudes and abilities); and

3. Developmental (it creates with the age and experience).

A study led by Martins et.al. ${ }^{9}$ stated that in certainty emotional intelligence meets each of the three criteria stated above.

Hunt and Fitzgerald ${ }^{10}$ implied that emotional intelligence is the subset of social intelligence that incorporates the capacity to screen one's own and others' sentiments and emotions, to separate them and to utilize this data to guide one's reasoning and activities. In addition, emo- tional intelligence incorporates the capacity to watch, perceive and comprehend one's own emotions and the emotions of others and to make a difference between one's own emotions and those of others. In the perspective of Harms and Crede ${ }^{4}$, individuals who are emotionally and socially astute can comprehend and convey what needs be to effectively adapt to requests of everyday life.

\subsection{Models of Emotional Intelligence}

\subsubsection{Ability Model}

This model was introduced by Salovey and Mayer's. The ability-based model describes emotions as valuable wellsprings of data that help an individual to comprehend and explore the social environment ${ }^{\underline{11}}$. In the view of Bradberry and $\mathrm{Su}^{12}$, the ability model suggests that individuals vary in their ability to process information of an emotional nature and in their ability to relate emotional preparing to a more extensive cognizance. This ability is seen to show itself in certain versatile practices. Salovey and Grewal ${ }^{13}$ purported that the ability model incorporates four sorts of abilities:

1. Perceiving emotions: the ability to perceive and interpret emotions in confronts pictures, voices, and social ancient rarities - including the ability to recognize one's own emotions. Perceiving emotions address a major part of emotional intelligence, as it makes all other handling of emotional data conceivable.

2. Utilising emotions: the ability to handle feelings to support distinctive subjective activities, for instance, deduction and critical considering. The emotionally shrewd individual can underwrite totally upon his or her changing dispositions remembering the ultimate objective to best fit the occupation that should be finished.

3. Understanding emotions: the ability to understand feeling and to recognize puzzled associations among emotions. Case in point, understanding feelings conceal the capacity to be tricky to slight assortments amongst feelings, and the capacity to see and depict how emotions develop after some time. 
4. Managing emotions: the ability to direct emotions in both ourselves and in others. In this way, the emotionally shrewd individual can saddle emotions, even negative ones, and manage them to achieve arranged destinations.

\subsubsection{Mixed Model}

This model was presented by Daniel Goleman that concentrates on emotional intelligence as a wide exhibit of abilities and skills that drive leadership performance. According to Joseph et al $\frac{14}{}$, Goleman's model layouts five primary constructs of emotional intelligence:

1. Self-awareness: the capacity to know one's emotions, qualities, shortcomings, drives qualities and objectives and perceive their effect on others while utilising hunches to guide choices.

2. Self-regulation: includes controlling or diverting one's troublesome emotions and driving forces and adjusting to evolving circumstances.

3. Social skill: overseeing connections to move individuals in the coveted bearing.

4. Empathy: considering other individuals' emotions particularly when settling on choice.

5. Motivation: being headed to accomplish for accomplishment.

Goleman incorporates an arrangement of emotional capabilities inside each construct of emotional intelligence. Emotional skills are not inborn gifts, but instead educated capacities that must be taken a shot at and can be created to accomplish extraordinary performance. Goleman places that people are conceived with a general emotional intelligence that decides their potential for learning emotional competencies ${ }^{14}$.

\subsubsection{Trait Model}

Petrides proposed a hypothetical refinement amongst the ability based model and a trait based model of EI and has been building up the last over numerous years in various publications ${ }^{15}$. According to Kluemper $\frac{16}{16}$, trait emotional intelligence is a star grouping of emotional self-discernments situated at the lower levels of personality. Moreover, trait emotional intelligence alludes to an individual's self-view of their emotional abilities. This meaning of emotional intelligence includes behavioural demeanours and self-saw abilities and is measured independent from anyone else report, instead of the ability based model which alludes to genuine abilities, which have demonstrated exceptionally impervious to experimental estimation. Trait emotional intelligence ought to be examined inside a personality framework $\mathrm{k}^{17}$.

In the view of Vernon et.al. $\frac{18}{}$, the trait emotional intelligence model is general and subsumes the Goleman model discussed previously. The conceptualization of emotional intelligence as a personality trait prompts a construct that lies outside the scientific categorization of human intellectual ability. This is a critical refinement in as much as it bears specifically on the operationalization of the speculations and theories that are figured about it.

\subsection{Emotional Intelligence in the Workplace}

Emotional intelligence can be valuable in numerous regions of life. Be that as it may, the use of its handiness has been most documented in the professional workplace. Cherniss and Goleman ${ }^{19}$ represented four primary reasons why the workplace would be a coherent setting for assessing and enhancing emotional intelligence capabilities:

1. Emotional intelligence skills are basic for achievement in many occupations.

2. Numerous grown-ups enter the workforce without the skills important to succeed or exceed expectations at their employment.

3. Employers have the built up means and inspiration for giving emotional intelligence training.

4. Most grown-ups spend the greater part of their waking hours at work.

According to Nunnally and Bernstein ${ }^{20}$, a solid enthusiasm for the expert utilizations of Emotional Intelligence is obvious in the way organizations have grasped emotional thoughts. Broad investigation in the field of emotional intelligence has concentrated on leadership, a crucial workplace quality. Ko Seon Hee ${ }^{21}$ suggests that to improve service more emphasis should be placed on 
psychological compensation which comes in the form of showing empathy which is a part of EI, to the customer and tuning in to what they have to say. A number of subcategories of emotional states associated with primary angry emotion often lead to confusion in its detection $\frac{22}{}$, to maintain a healthy workplace environment it is important to manage anger and other negative emotions which is a part of EI. A research performed by Cherniss $s^{23}$ reported that leaders who could build up common trust, regard, and certain glow and affinity with individuals from their gathering were more viable. This outcome is not astonishing given that numerous studies have contended that compelling leadership on a very basic level relies on the leader's capacity to take care of the unpredictable social issues which can emerge in organizations.

\subsection{Job Performance}

According to Berman et.al. $\underline{24}$ job performance contains any practices or activities that added to the accomplishment of undertaking or organizational objective. Representatives with great performance can be identified with particular business results, for example, better money related performance, gainful workforce, and better degrees of consistency. Several studies on the relationship between emotional intelligence and work performance have been led ${ }^{25}$. In the view of Nasurdin, Khuan ${ }^{26}$, job performance is normally portrayed as far as recognizable and non-recognizable practices which can be evaluated. Berman et $\mathrm{a}^{\mathbf{2 4}}$ stated that it is a multidimensional idea which depicts how one finishes an assignment, concentrating on productivity, abilities utilized, activity and used resources. According to Rich et al ${ }^{\frac{27}{}}$, job performance is an activity that includes procedure and item (final outcome). The individual procedure can be affected by general performance of an organization. It is activities that decide one's performance as well as outer elements, for example, resources, organizational society, money related, political and social components. In the perspective of Viswesvaran ${ }^{28}$, job performance consists of 10 dimensions. Dependent upon the method for the employment, certain dimensions are more imperative than others. Those dimension basically 36 cover with the eight dimensions highlighted by Campbell et.al..29 and which are very much acknowledged. The dimensions are described in the Figure 1.

\begin{tabular}{ll}
\hline 10 DIMENSIONS (Viswesvaran, 1993) & 8 DIMENSIONS (Campbell et al., 1993) \\
\cline { 1 - 2 } - Overall job performance & - Job-specific task proficiency \\
- Productivity & - Wonjob-specific task proficiency \\
- Effort & - Demonstrating effort \\
- Job-related knowledge & - Maintaining personal discipline \\
- Interpersonal skills & - Facilitating peer and team performance \\
- Quality & - Supervision/leadership \\
- Leadership & Management/administrative \\
- Rule following & \\
- Administrative skills & \\
\hline
\end{tabular}

Figure 1. Job performance dimensions (Viswesvaran, 1993; Campbell et al, 1993). 


\subsection{Emotional Intelligence and Job Performance}

According to Cote and Miners ${ }^{30}$ research worldwide and in various areas shows that top performers can be isolated from normal ones by taking cognisance of their emotional intelligence. Joseph and Newman ${ }^{31}$ purported that the individuals who are emotionally intelligent take after their qualities and trust in consistent learning and concentrate on imparting vision. People with a fixed mindset are likely to show less resilience when they face obstacles. The significance of emotional intelligence, its immediate positive relationship with job performance and its prescient legitimacy in regards to future performance ${ }^{33}$ drove research attempts and supported arguments on the theme around the world. According to Boyatzis and Taylor ${ }^{3}$, there are two main models of emotional intelligence the ability-based emotional intelligence model and the trait-based (mixed) emotional intelligence model. In the view of Boyel et.al. $\frac{34}{4}$ emotional intelligence creates innovational inventiveness in people and thus, helps in the change individuals' job performance. Furthermore, job performance is encouraging the communication inside organization which is another capacity of emotional intelligence ${ }^{35}$. Emotional intelligence has the ability to better clarify the general population's workplace performance. Its part is to change endeavours, management viability, training and the performance of organization inside the organization, (for example, bank, school, organization).

It is of principal criticalness to do the studies on emotional intelligence, the total effect in the change of the execution to better understand the region of Human Resource Development (HRD) and the part it plays in the advancement of the key capacity of organizations. With respect to calling decision, the emotional intelligence helps individuals to pick their job appropriately properly and helps them to succeed in the organization by increasing the degree of job performance. In the perspective of Rosete and Ciarrochi ${ }^{36}$ results which identify with the work, for instance, job performance may be impacted by Emotional Intelligence. Jacques ${ }^{37}$ expressed that the forecast of emotional intelligence for individuals is productive in life and work. Because of the impact of emotional intel- ligence on all aspects of people's work life, abnormal state had emotional intelligence representatives are considered as star performers. Thus, as expressed in the past areas, there is a positive relationship between's emotional intelligence and job performance. A dominant part of tests done already have underpins for the relationship between these two variables, in particular emotional intelligence and job performance $\mathrm{e}^{38}$.

\section{Significance of the Study}

This research is significant to banking, power, health care, IT and advertising sectors in India to develop a model for Emotional Intelligence and Job Performance. Moreover, it is of foremost significance to do the studies on emotional intelligence, its effects and the impact in the change of the performance to better comprehend the area of Industrial Psychology and the part it plays in the advancement of the vital ability of organizations.

\section{Methodology}

The research examines the relationships between EI and job performance of managers from five sectors like banking, power, health care, IT and advertising. Descriptive research design is employed to explain the characteristic of sample that are used in a research ${ }^{39}$. Thus, descriptive research has been employed in this research by the researcher. As three elements are elements are involved in the descriptive research namely observation, questionnaires and surveys, this has facilitated in outlining the idea from several measures of tests.

\subsection{Sample and Data Collection}

A sample of 685 middle management employees' was selected through random sampling. Each respondent was personally contacted and requested to fill the questionnaire. The respondents were middle management employees' i.e. team leaders, assistant managers, managers, senior managers, etc. from various organizations in India. 


\subsection{Measures}

\subsubsection{Deepa Krishnaveni Emotional Intelligence Test DKEIT}

Krishnaveni and Ranganath ${ }^{41}$ developed a self-report emotional scale which is called as Deepa Krishnaveni Emotional Intelligence Test (DKEIT) has been employed as a tool for measurement of EI among the employees. This scale comprises eighteen items that represent adaptive tendency toward emotional intelligence. Each item in the questionnaire described a work-related behaviour. The higher the score, the greater the tendency an individual possessed to show emotionally intelligent behaviour. DKEIT is divided into three constituents of EI namely perception, appraisal, and regulation. These elements are described below:

1. Emotional perception is the capacity of a person to translate the different emotional boosts which are a consequence of the distinctive elements of his/her surroundings and sort out them for further handling.

2. Emotional appraisal is characterised as the capacity of a person to comprehend the emotional data supplied by the perception procedure and further assess it subjectively, concerning his/ her surroundings, to choose the suitable reactions to the boosts.

3. Emotional regulation is said to be the capacity of a person to manage the reaction sustained by the appraisal system in concurrence with the individual/object/circumstance to evoke further constructive outcomes.

\subsubsection{Job Performance Inventory (JPI)}

Job Performance Inventory (JPI) was utilised to evaluate the performance of the employees. The makers figured this instrument to measure the general job performance of the employees. In this instrument, seventeen items were utilised to evaluate the job performance of the worker wherein the quick supervisor or manager surveyed these practices on a five-point scale ranging from 2 (always) to -2 (never). The higher score demonstrates that the rep- resentative is a good performer. JPI is separated into four constituents in particular accuracy, competence, punctuality and teamwork, the scores of these four segments definitely anticipate an individual's job performance.

1. Accuracy: Accuracy is liberty from mistake and closeness to truth caused by the activity of meticulous consideration or due ingenuity.

2. Competence: A group of related capacities, duties, learning, and abilities that empower a man to act viable in a job or circumstance.

3. Punctuality: Punctuality is the normal for having the capacity to finish a required assignment or satisfy a commitment before or at a formerly assigned time.

4. Teamwork: The way toward working cooperatively with a team of individuals to accomplish an objective is teamwork. It is regularly a critical piece of business, as it is essential for partners to function admirably together, attempting their best in any condition. Teamwork implies that individuals will attempt to coordinate, utilising their individual abilities and giving helpful input, in spite of any individual clash between people.

\section{Results}

Table 1 present the descriptive statistics and inter correlations matrix of the research variable. The aim of present study is to explore the relationship between the emotional intelligence and Job Performance. To realize this objective, Pearson's product-moment correlation is computed. The hypothesis of the study states that there is a relationship between EI and Job Performance. As hypothesized, there were significant and positive correlations between employees Job Performance and Emotional Intelligence $r$ $=0.746(p<0.01)$, Emotional Perception $r=0.434(p<$ $0.01)$, Emotional Appraisal $\mathrm{r}=0.370(p<0.01)$, Emotional Regulation $\mathrm{r}=0.665(p<0.01)$. The components of Job Performance i.e., punctuality, competence, accuracy and team work also show significant positive correlations with Emotional Intelligence and its components. Table 1 show that Punctuality of an employee is significantly and posi- 
tively correlated to Emotional Intelligence $r=0.633$ ( $p<$ $0.01)$ Emotional Perception $r=0.370(p<0.01)$, Emotional Appraisal $\mathrm{r}=0.296(p<0.01)$ and Emotional Regulation $r=0.560(p<0.01)$. Competence of an employee is significantly and positively related to Emotional Intelligence of a person $r=0.652(p<0.01)$ Emotional Perception $r$ $=0.370(p<0.01)$, Emotional Appraisal $\mathrm{r}=0.305(p<$ $0.01)$ and Emotional Regulation $r=0.582(p<0.01)$. The correlations also show that the accuracy with which an employee works has significant and positive relationship with Emotional Intelligence $r=0.645(p<0.01)$ Emotional Perception $\mathrm{r}=0.376(p<0.01)$, Emotional Appraisal $\mathrm{r}=$ $0.288(p<0.01)$ and Emotional Regulation $\mathrm{r}=0.576(p<$ 0.01 ). The last component of Job Performance i.e. Team
Work is also show significant positive correlations with Emotional Intelligence $r=0.697(p<0.01)$ Emotional Perception $\mathrm{r}=0.408(p<0.01)$, Emotional Appraisal $\mathrm{r}$ $=0.381(p<0.01)$ and Emotional Regulation $r=0.599$ $(p<0.01)$. This state, employees with higher scores on Emotional Intelligence, Emotional Perception, Emotional Appraisal, and Emotional Regulation are significantly more likely to be punctual and competent, accurate, team players and over all good at job performance. On this basis the research hypothesis is supported and it motivated the investigator to use Stepwise Multiple Linear Regression to establish the linear relationships between the dependent and independent variable.

Table 1. Correlations analysis.

\begin{tabular}{|c|c|c|c|c|c|c|c|c|c|c|c|}
\hline & Variable & Mean & SD & $\mathbf{1}$ & $\mathbf{2}$ & $\mathbf{3}$ & $\mathbf{4}$ & $\mathbf{5}$ & $\mathbf{6}$ & $\mathbf{7}$ & $\mathbf{8}$ \\
\hline 1 & Perception & 14.85 & 4.164 & & & & & & & & \\
\hline 2 & Appraisal & 17.56 & 2.450 & $.169^{* *}$ & & & & & & & \\
\hline 3 & Regulation & 50.63 & 7.784 & $.203^{* *}$ & $.239^{* *}$ & & & & & & \\
\hline 4 & $\begin{array}{c}\text { Emotional } \\
\text { Intelligence }\end{array}$ & 83.04 & 10.472 & $.588^{* *}$ & $.479^{* *}$ & $.880^{* *}$ & & & & & \\
\hline 5 & Punctuality & 3.69 & 2.052 & $.370^{* *}$ & $.296^{* *}$ & $.560^{* *}$ & $.633^{* *}$ & & & & \\
\hline 6 & Competence & 3.23 & 2.033 & $.370^{* *}$ & $.305^{* *}$ & $.582^{* *}$ & $.652^{* *}$ & $.663^{* *}$ & & & \\
\hline 7 & Accuracy & 3.47 & 1.897 & $.376^{* *}$ & $.288^{* *}$ & $.576^{* *}$ & $.645^{* *}$ & $.639^{* *}$ & $.751^{* *}$ & & $.834^{* *}$ \\
\hline 8 & Team Work & 5.45 & 3.832 & $.408^{* *}$ & $.381^{* *}$ & $.599^{* *}$ & $.697^{* *}$ & $.691^{* *}$ & $.757^{* *}$ & $.735^{* *}$ & $.934^{* *}$ \\
\hline
\end{tabular}

**. P 0.01 level (2-tailed). 
Building on the significant bivariate relationships shown in Table 1, multiple regression analysis was conducted to examine the combined effect of the significant predictors on the outcome variables. Multiple regression analysis also controls the inter-correlations found between the predictors in Table 1 . $\mathrm{R}$ square, the adjusted $\mathrm{R}$ square and $\mathrm{F}$ values have been used when reporting the regression analyses. According to the hypothesis, employees with higher scores on Emotional Intelligence, Emotional Perception, Emotional Appraisal, and Emotional Regulation are more likely to be better job performers than others. Stepwise multiple linear regression technique is applied to dependent variable Job Performance. Emotional Perception, Emotional Appraisal and Emotional Regulation were entered into a regression equation as independent variables.

Table 2 shows that the value of $\mathrm{R}$ increases in the successive step and it is highest $(\mathrm{R}=.557)$ in model 3 in which the explanatory variables Emotional Perception, Emotional Appraisal and Emotional Regulation all three are included. This makes us accept the third regres- sion model where combined relationship of Emotional Perception, Emotional Appraisal and Emotional Regulation on Job Performance was statistically significant $F=285.393(\mathrm{p}=0.000)$ and the value of $\mathrm{R}$ Square $=$ 0.557 which predicts that explanatory variables Emotional Perception, Emotional Appraisal and Emotional Regulation causes $55.7 \%$ variance on the employees Job Performance with an Adjusted $R^{2}=0.555$. The Beta weights for all three components of EI were statistically significant indicating that emotional Perception $(\beta=.608$, $p=0.000)$, Emotional Appraisal $(\beta=.676, p=0.000)$ and Emotional Regulation $(\beta=.618, p=0.000)$ added to the variance in the job performance of the employee. The summary of successive models of stepwise multiple linear regressions along with the F value from ANOVA are given in Table 2. To know the relationship between EI and the four components of Job performance i.e. punctuality, competence, accuracy and team work, the authors carried out stepwise multiple regression on the Dependent variables (punctuality, competence, accuracy and team work) and EI. The relationship of Punctuality with EI was

Table 2. Model summary.

\begin{tabular}{|c|c|c|c|c|c|c|c|c|}
\hline Model & $\mathbf{R}$ & R Square & $\begin{array}{c}\text { Adjusted R } \\
\text { Square }\end{array}$ & $\begin{array}{c}\text { Std. Error of } \\
\text { the Estimate }\end{array}$ & F & Sig. & t & Sig. \\
\hline 1 & $.655^{\mathrm{a}}$ & .429 & .428 & 6.603 & 513.626 & $.000^{\mathrm{a}}$ & & \\
\hline 2 & $.724^{\mathrm{b}}$ & .524 & .522 & 6.036 & 374.852 & $.000^{\mathrm{b}}$ & 17.113 & .000 \\
\hline 3 & $.746^{\mathrm{c}}$ & .557 & .555 & 5.826 & 285.393 & $.000^{\mathrm{c}}$ & 18.338 & .000 \\
\hline \\
a. Predictors: (Constant), Regulation \\
b. Predictors: (Constant), Regulation, Perception \\
c. Predictors: (Constant), Regulation, Perception, Appraisal \\
\hline
\end{tabular}


statistically significant $F=456.061(\mathrm{p}=0.000)$ and the value of $\mathrm{R}$ Square $=0.400$ which predicts that Emotional Intelligence causes $40 \%$ variance on a person's punctuality with an Adjusted $R^{2}=0.400$. The Beta weights for EI ( $\beta=$ $0.124)$ are significant where $t=21.356(p=0.000)$. EI is again positively and significantly related to Competence where $\mathrm{F}=503.765(\mathrm{p}=0.000)$ and the value of $\mathrm{R}$ square = 0.424 that is, EI causes $42.4 \%$ variance on a person's competence with an Adjusted $\mathrm{R}^{2}=0.424$ and beta weights $\beta=$ 0.126 are also significant where $t=22.445(p=0.000)$. The third component of Job Performance i.e. accuracy is also positively and significantly related to EI with $\mathrm{R}$ Square $=0.416$, Adjusted $\mathrm{R}^{2}=0.415$ and $\mathrm{F}=486.747(\mathrm{p}=0.000)$, it states that EI causes $41.6 \%$ variance in the employees accuracy in terms of work. Team work is a part of Job Performance and it is related significantly to EI where $\mathrm{R}$ Square $=0.486$, Adjusted $\mathrm{R}^{2}=0.485$ and $\mathrm{F}=644.669(\mathrm{p}=$ 0.000 ), that is EI causes $48.6 \%$ variance when it comes to team work.

\section{Discussions}

The emotional intelligence of middle level management was assessed with the help of a questionnaire and job performance through supervisor ratings to avoid common method biases. In accordance with theoretical predictions, emotional intelligence along with all its components; Emotional Perception, Emotional Appraisal and Emotional Regulation was significantly related to all indicators of work performance, including: Punctuality, competence, accuracy and team work. Although the main analyses focused on total emotional intelligence, we found that all three emotional intelligence subscales, were associated with all of the three outcomes. Job performance is highly influenced by an employee's ability to use emotions to further facilitate their performance, which is also one of the dimensions of $\mathrm{EI}^{41,42}$. Our results extend past research that revealed associations between self-report measures of EI and job performance ${ }^{43}$ and also between ability measures of EI and the quality of social interactions outside of the workplace ${ }^{44}$. According to our study, Punctuality is positively related to EI that is, the employee who rated himself high on EI is more likely to be punctual than the employee who is rated low on EI. An employee who scores high on EI was found to me more competent in his work as compared to the employees who score less on EI. Accuracy of work also depends upon the EI of the employee, the higher the employee scores on EI the more accurate he is with his work. Employees with high EI are said to have better working relationships with other employees and they reflect higher integrity ${ }^{36}$ because they can foster better and positive interactions which thereby lead to better performance ${ }^{45,42}$. The results of our study are in line with this and state that employee with high EI are better at team work and working in groups as compared to the ones who score low on EI. Not only overall EI of an employee but the components of EI are also positively related to his job performance. Emotional Perception, Emotional Appraisal and Emotional regulation all contribute towards a better job performance of the employee.

\section{Managerial Implications}

Emotional intelligence is hypothesized to influence the success with which employees interact with their colleagues, the strategies they use to manage conflict, stress, and overall job performance ${ }^{46,47}$. Preliminary findings suggest that EI positively contributes towards several aspects of job performance. In a study on analysts and clerical employees from the finance department of a health insurance company, the employee who scored higher on EI received greater merit pay increases and had higher company rank as compared to the employees with lower EI scores. Employees with higher scores on EI scale also received better peer or supervisor ratings of interpersonal facilitation, stress tolerance, and leadership potential than those with lower scores of EI ${ }^{47}$. Similarly, among middle and high school teachers, EI scores were associated positively with job satisfaction and negatively with burnout. These associations were mediated by teacher reports of experiencing positive emotions in school and their perceived support from their school principal ${ }^{48}$. Emotional intelligence has been associated with managers who conduct themselves in ways that are supportive of the goals of the organisation, according to the ratings of their supervisors ${ }^{49}$. EI scores for 38 manufacturing supervisors' 
managerial performance had a positive correlation with managerial performance ratings by nearly 1,300 employ$e^{e} \mathrm{~s}^{50}$. EI scores of senior executives predicted leadership effectiveness as rated by managers ${ }^{36}$. With few exceptions, most of the associations in the above studies were statistically significant after controlling for gender, age, verbal ability, education, and personality traits. More thorough discussions on the role of EI in the workplace, including both job performance and leadership, can be found in many other studies ${ }^{34,46,47}$.

\section{Conclusion}

This study examines the relationship between emotional intelligence and job performance. It could be observed from this research that higher emotional intelligence develops superior relationships in work. Joseph and Newman ${ }^{31}$ observed that the individuals who are emotionally intelligent take after their qualities and trust inconsistent learning and concentrate on imparting vision. Emotional intelligence has the ability to better clarify the general population's workplace performance. On which Boyel et.al. ${ }^{34}$ stated that emotional intelligence creates innovation inventiveness in people and thus, helps in the change in individuals' job performance. Hence, the significance of emotional intelligence, its immediate positive relationship with job performance and its prescient legitimacy in regards to future performance drove research attempts and supported arguments on the theme around the world because they can foster better and positive interactions which thereby lead to better performance.

The present study is limited by its sample population as the sample was drawn from only five services sectors in India which do not represent all the service sectors. Therefore our findings should be interpreted with caution until they are replicated in other sectors as well. Furthermore, we should note that we did not measure work performance directly but with the help of supervisor rated questionnaire to avoid bias. Nonetheless, our results provide preliminary evidence that emotional intelligence, measured as a set of abilities, is associated with important positive work outcomes and leads to better job performance.

\section{References}

1. Boyatzis RE, Oosten EV. Developing Emotionally Intelligent Organizations. 7th Edition, London: Kogan Page Publishers, 2002.

2. Dursun P, Emul M, Gencoz F. A Review of Literature on Emotional Facial Expression and its Nature, New/Yeni Symposium Journal. 2010; 48(3):207-15.

3. Boyatzis RE, Taylor SN. Developing Emotional Intelligence. Upper Saddle River, N. J.: Pearson Education, 2003.

4. Harms PD, Crede M. Remaining Issues in Emotional Intelligence Research: Construct Overlap, Method Artifacts and Lack of Incremental Validity, Industrial and Organizational Psychology: Perspectives on Science and Practice. 2010; 3(2):154-58.

5. Coleman A. A Dictionary of Psychology. 3rd Edition. Oxford University Press, 2008.

6. Barbey AK, Colom R, Grafman J. Distributed Neural System for Emotional Intelligence Revealed by Lesion Mapping, Social Cognitive and Affective Neuroscience. 2012; 9(3):265-72.

7. Goleman D. The Brain and Emotional Intelligence: New Insights, 2011.

8. Caruso DR. Emotions and the Ability Model of Emotional Intelligence. Hauppauge, NY: Nova Science Publishers, 2008.

9. Martins A, Ramalho N, Morin E. A Comprehensive Meta-Analysis of the Relationship between Emotional Intelligence and Health, Journal of Personality and Individual Differences. 2010; 49(6):554-64.

10. Hunt J, Fitzgerald M. The Relationship between Emotional Intelligence and Transformational Leadership: An Investigation and Review of Competing Claims in the Literature, American International Journal of Social Science. 2013; 2(8):30-38.

11. Fiori M, Antonakis J. The Ability Model of Emotional Intelligence: Searching for Valid Measures, Personality and Individual Differences. 2011; 50(3):329-34.

12. Bradberry T, Su L. Ability-Versus Skill-Based Assessment of Emotional Intelligence. Psicothema. 2003; pp 59-66.

13. Salovey P, Grewal D. The Science of Emotional Intelligence; Current Directions in Psychological Science. 2005; 6(1).

14. Joseph DL, Jin J, Newman DA, O'Boyle EH. Why Does SelfReported Emotional Intelligence Predict Job Performance? A Meta-Analytic Investigation of Mixed EI, Journal of Applied Psychology. 2015; 100:298-342. 
15. Austin EJ. A Reaction Time Study of Responses to Trait and Ability Emotional Intelligence Test Items, Personality and Individual Differences. 2008; 46(3):381-83.

16. Kluemper DH. Trait Emotional Intelligence: The Impact of Core-Self Evaluations and Social Desirability, Personality and Individual Differences. 2008; 44(6):1402-12.

17. Kokkinos, Constantinos M, Kipritsi, Eirini. The Relationship between Bullying, Victimization, Trait Emotional Intelligence, Self-Efficacy and Empathy among Preadolescents, Social Psychology of Education. 2011; 15(1):41-58

18. Vernon PA, Petrides KV, Bratko D, Schermer JA. A Behavioral Genetic Study of Trait Emotional Intelligence, Emotion. 2008; 8(5):635-42.

19. Cherniss C, Goleman D. Bringing Emotional Intelligence to the Workplace, Personality and Individual Differences. 2009; 3:1477-90.

20. Nunnally JC, Bernstein IH. Emotional Intelligence: Issues in Paradigm Building. San Francisco: Jossey Bass, 2010.

21. Ko Seon Hee. The Structural Relationship among Service Failure, Service Recovery, Emotional Reaction and Recovery Satisfaction in the Airline Service, Indian Journal of Science and Technology. 2016 July; 9(26). Doi: 10.17485/ ijst/2016/v9i26/9727.

22. Hemanta Kumar Palo, Jyoti Mohanty, Mihir Narayan Mohanty, Mahesh Chandra. Recognition of Anger, Irritation and Disgust Emotional States based on Similarity Measures, Indian Journal of Science and Technology. 2016 Oct; 9(38). Doi: 10.17485/ijst/2016/v9i38/102971.

23. Cherniss C. Social and Emotional Competence in the Workplace. The Handbook of Emotional Intelligence. San Francisco: Jossey-Bass, 2010.

24. Berman EM, Bowman JS, West JP, Wart MRV. Motivation: Possible, Probable or Impossible? Human Resource Management in Public Service: Paradoxes, Processes and Problems. California: SAGE Publications, 2010.

25. Feddock CA, Hoellein AR, Wilson JF, Caudill TS, Griffith $\mathrm{CH}$. Do PRESSUre and Fatigue Influence Resident Job Performance? Medical Teacher. 2007; 29(5):495-97.

26. Nasurdin AM, Khuan SL. Organizational Justice as an Antecedent of Job Performance, International Journal of Business. 2007; 9(3):325-43.

27. Rich BL, LePine JA, Crawford ER. Job Engagement: Antecedents and Effects on Job Performance, Academy of Management Journal. 2010; 53(3):617-35.

28. Viswesvaran C. Modeling Job Performance: Is there a General Factor? Doctoral Dissertation, University of Iowa, 1993.
29. Campbell JP, McCloy RA, Oppler, SH, Sager CE. A Theory of Performance. In: Personnel Selection in Organizations San Francisco, N. Schmitt and W. C. Borman (Eds.), CA: Jossey Bass, 1993, p. 35-70.

30. Cote S, Miners CTH. Emotional Intelligence, Cognitive Intelligence and Job Performance, Administrative Science Quarterly. 2006; 51(1):1-2.

31. Joseph DL, Newman DA. Emotional Intelligence: An Integrative Meta-Analysis and Cascading Model, Journal of Applied Psychology. 2010; 95(1):54-78.

32. Chang Seek Lee, Yeoun Kyung Hwang. Structural Relationship among Social Support, Hope, Stress and Emotional Intelligence of Rural Elementary School Students in Korea: the Mediating Effect of Self-esteem, Indian Journal of Science and Technology. 2016 July; 9(25). Doi: 10.17485/ijst/2016/v9i25/97168.

33. Farh CC, Tesluk S. Emotional Intelligence, Teamwork Effectiveness, and Job Performance: The Moderating Role of Job Context, Journal of Applied Psychology. 2012; 124(2):262-74.

34. Boyel E, Humphery RH, Pollack JM, Hawver, Story PA. The Relation between Emotional Intelligence and Job Performance: A Meta-Analysis, Journal of Organizational Behaviour. 2011; 32:788-818.

35. Lopes PN, Cote S, Grewal D, Salovey P, Kadis J, Gall M. Evidence that Emotional Intelligence is Related to Job Performance, Interpersonal Facilitation, Affect and Attitudes at Work, and Leadership Potential, Psicothema, 2006; 18:132-38.

36. Rosete D, Ciarrochi J. Emotional Intelligence and its Relation to Workplace Performance Outcomes to Leadership Effectiveness, Leadership and Organization Development Journal. 2005; 26:388-99.

37. Jacques ET. The Relationships between Emotional Intelligence and the Academic Performance and Selection of a Major of College Students, 2009. Retrieved July 13. 2010, from PreQuest Database.

38. Harris NV. Is Emotional Intelligence the Key to Medical Sales Success? The Relationship between Emotional Intelligence and Sales Performance, 2009. Retrieved from: ProQuest Database.

39. Saunders M, Lewis P, Thornhill A. Research Methods for Business Students. 5th Edition. Essex, England: Prentice Hall 2009.

40. Deepa R, Krishnaveni R. Development and Validation of an Instrument for Measuring the Emotional Intelligence of Individuals in the Work Environment - In the Indian 
Context, The International Journal of Educational and Psychological Assessment. 2011 May; 7(2).

41. George JM, Brief AP. Motivational Agendas in the Workplace: The Effects Of Feelings on Focus of Attention and Work Motivation, Research in Organizational Behavior. 1996; 18:75-109.

42. Dhani P, Sharma T. Relationship between Emotional Intelligence and Job Performance. In: New Dimensions for Dynamic Business Practices. Shroff Publishers and Distributors Pvt. Ltd., 2016, p. 289-91.

43. Law KS, Wong CS, Song LJ. The Construct and Criterion Validity of Emotional Intelligence and its Potential Utility for Management Studies, Journal of Applied Psychology. 2004; 89:483-96. Doi: 10.1037/0021-9010.89.3.483.

44. Lopes PN, Brackett MA, Nezlek JB, Schutz A, Sellin, I, Salovey P. Emotional Intelligence and Social Interaction, Personality and Social Psychology Bulletin. 2004; 30:101834. Doi: 10.1177/0146167204264762.

45. Wong CS, Law KS. The Effects of Leader and Follower Emotional Intelligence on Performance and Attitude: An Exploratory Study, Leadership Quarterly. 2002; 13:243-74. Doi: 10.1016/S1048-9843(02)00099-1.
46. Ashkanasy NM, Daus CS. Emotion in the Workplace: The New Challenge for Managers, Academy of Management Executive. 2002; 16:76-86.

47. Lopes PN, Co^te' S, Grewal D, Salovey P, Kadis J, Gall M. Evidence that Emotional Intelligence is Related to Job Performance, Interpersonal Facilitation, Affect and Attitudes at Work, and Leadership Potential, Psicothema. 2006; 18:132-38.

48. Brackett MA, Palomera R, Mojsa Kaja J, Reyes MR, Salovy P. Emotion-Regulation Ability, Burnout, and Job Satisfaction among British Secondary-School Teachers, Psychology in the Schools. 2010; 47(4):406-17. Retrieved from: http://search.proquest.com/docview/622169747?acc ountid $=14568$.

49. Cote S, Miners CT. Emotional Intelligence, Cognitive Intelligence, and Job Performance, Administrative Science Quarterly. 2006; 51:1-28.

50. Kerr R, Gavin J, Heaton N, Boyle E. Emotional Intelligence and Leadership Effectiveness, Leadership and Organization Development Journal. 2005; 27(4):265-79. 